\title{
The Importance of Minor Salivary Gland Biopsy in Sjögren Syndrome Diagnosis and the Clinicopathological Correlation
}

\author{
Gürdeniz SERINN ${ }^{1}$, Gonca KARABULUT², Yasemin KABASAKAL², Gülşen KANDiLOĞLU³, Taner AKALIN³
}

'Department of Pathology, Buca Gynaecology, Obstetrics and Pediatrics Hospital, IZMiR, TURKEY,

Department of ${ }^{2}$ Rheumatology and ${ }^{3}$ Pathology, Ege University, Faculty of Medicine, IZMIR, TURKEY

\section{ABSTRACT}

Objective: Minor salivary gland biopsy is one of the objective tests used in the diagnosis of Sjögren syndrome. The aim of our study was to compare the clinical and laboratory data of primary and secondary Sjögren syndrome cases with a lymphocyte score 3 and 4 in the minor salivary gland biopsy.

Material and Method: Data from a total of 2346 consecutive minor salivary gland biopsies were retrospectively evaluated in this study. Clinical and autoantibody characteristics of 367 cases with lymphocyte score 3 or 4 and diagnosed with primary or secondary Sjögren syndrome were compared.

Results: There was no difference between lymphocyte score 3 and 4 primary Sjögren syndrome patients in terms of dry mouth, dry eye symptoms and Schirmer test results but Anti-Ro and Antinuclear Antibody positivity was statistically significantly higher in cases with lymphocyte score $4(\mathrm{p}=0.025, \mathrm{p}=0.001)$. Anti-Ro test results were also found to be statistically significantly higher in secondary Sjögren syndrome patients with lymphocyte score $4(\mathrm{p}=0.048)$.

Conclusion: In this study, the high proportion of cases with negative autoantibody but positive lymphocyte score is significant in terms of showing the contribution of minor salivary gland biopsy to Sjögren syndrome diagnosis. Lymphocyte score 3 and 4 cases were found to have similar clinical findings but a difference regarding antibody positivity in primary Sjögren syndrome. We believe that cases with lymphocyte score 4 may be Sjögren syndrome cases whose clinical manifestations are relatively established and higher autoantibody levels are therefore found.

Key Words: Sjögren syndrome, Minor salivary gland, Biopsy, Autoantibodies

\section{INTRODUCTION}

Sjögren Syndrome (SS) is a chronic, autoimmune disorder characterized by lymphocytic infiltration of all exocrine glands. The salivary glands are especially involved. Lymphocytic infiltration disrupts the functions of the glandular epithelium and causes dry mouth (xerostomia) and dry eye (xerophthalmia) symptoms (1). The exocrinopathy is called primary SS if a concomitant autoimmune disease is absent, while cases where the exocrinopathy findings are observed together with any autoimmune disease (most commonly rheumatoid arthritis, systemic lupus erythematosus and systemic sclerosis) are named secondary SS (2). SS is reported to be the most common autoimmune disorder that is seen together with an autoimmune disease (3).

SS is one of the most common autoimmune diseases and affects approximately $1-3 \%$ of the general population. It is estimated that about half of the patients have never been

(Turk Patoloji Derg 2016, 32:65-69)

Received : 01.07.2015 Accepted : 30.11.2015 diagnosed (2). It can be seen in all age groups but is most common in the 4th and 5th decades. It is significantly more common in females. (F/M: 9/1) (4). Although the pathogenesis of SS is not fully understood, genetic disposition as well as environmental factors such as infections, hormones and vitamins are thought to play a role (2).

Various classification criteria including the combination of clinical findings, serologic tests and histopathological findings in the minor salivary glands are used for SS diagnosis. There is no accepted gold standard test for the diagnosis.

Minor salivary gland biopsy (MSGB) is one of the objective tests used in SS diagnosis. MSGB has been included in almost all classification criteria after identification of lymphocytic infiltration of the salivary glands by Chisholm and Mason in 1968. In that study, it was found that the presence of one lymphocytic focus at a minimum in

Correspondence: Gürdeniz SERİN

Buca Kadın Doğum ve Çocuk Hastalıkları Hastanesi,

Patoloji Bölümü, İZMİR, TURKEY

E-mail: drgurdeniz@gmail.com Phone: +90 5333680312 
every biopsy area of $4 \mathrm{~mm}^{2}$ was a characteristic finding of SS (5). The importance of MSGB has increased with the publication of the American European Consensus criteria in 2002. These criteria include the presence of at least one of the serological autoantibody (Anti-Ro or Anti-La) and characteristic MSGB findings in addition to subjective signs and symptoms of dry mouth and eye as a condition for diagnosis (6). Studies questioning the place of MSGB in the diagnosis and its reliability have also been published (7). There are few studies on the correlation between clinical and pathological findings in order to better identify biopsy indications. Some previous studies have been conducted by grouping lymphocyte score (LS) 1-2 and LS 3-4 cases $(7,8)$.

The aim of our study was to evaluate MSGB findings in patients with a preliminary SS clinical diagnosis, to compare the clinical and laboratory findings of the cases found to be MSGB LS 3 and 4 in primary and secondary SS, and to evaluate whether the two groups are similar in terms of clinical and laboratory findings.

\section{MATERIAL and METHOD}

A total of 2346 MSGBs referred to the Ege University Medical Faculty Pathology Department with a preliminary diagnosis of SS during seven consecutive years were retrospectively evaluated.

We included in the study the 367 patients for whom we could access the clinical and laboratory data of the 891 cases diagnosed with primary or secondary SS, and who had LS 3 or 4 in the MSGB. These patients were first divided into 2 groups as primary and secondary SS. Both groups were divided within themselves into subclasses as LS 3 and 4. The cases were compared in terms of dry mouth and eye symptoms, Schirmer test results, anti-Ro and Anti-La, Rheumatoid Factor (RF), and Antinuclear Antibody (ANA) positivity.

The MSGBs were histologically graded as recommended by Chisholm (5). Accordingly, the biopsy material needed to have a minimum size of $4 \mathrm{~mm}^{2}$ and contain a minimum of 4 assessable salivary gland lobes to be accepted as adequate. A cluster of cells with at least 50 lymphocytes was called a focus. Biopsies showing mild and dispersed lymphocytic infiltration were identified as LS 1, biopsies with moderate infiltration but without clusters of at least 50 lymphocytes as LS 2, biopsies containing one focus as LS 3 and biopsies containing more than one focus as LS 4 .

The SPSS 15.0 package software program was used for statistical analysis. Descriptive frequency tables and means were used for basic statistical analysis. Chi-square analysis was used to evaluate the significance of the difference between the ratios and logistic regression analysis was performed adjusting for the significant results of the Chisquare test. A $p$ value of $<0.05$ was considered statistically significant.

\section{RESULTS}

We retrospectively evaluated a total of 2346 MSGBs referred with a preliminary diagnosis of SS. The distributions of these biopsies according to Chisholm scoring are presented in Table I.

There were 367 cases for whom we could access the clinical data among the 891 cases diagnosed with SS with LS 3 or 4, and this group consisted of 341 (93\%) females and 26 (7\%) males with a mean age of 52.8 years.

The diagnosis was primary SS in 278 cases $(75.7 \%)$ and secondary SS in 89 (24.3\%) cases. Accompanying diseases in cases with secondary SS are shown in Table II.

There was no difference between the LS 3 and 4 cases regarding symptoms of dry mouth and Schirmer test results but Anti-Ro and ANA positivity was statistically significantly higher in cases with LS $4(\mathrm{p}=0.025$ and $\mathrm{p}=0.001$ ). ANA positive patients were 2.5 fold more likely to

Table I: Distributions of biopsies according to Chisholm scoring

\begin{tabular}{|c|c|}
\hline Lymphocyte score (Chisholm score) & $\mathbf{n}(\%)$ \\
\hline 1 & $469(20)$ \\
\hline $1-2$ & $170(7.2)$ \\
\hline 2 & $816(34.8)$ \\
\hline 3 & $391(16.7)$ \\
\hline 4 & $500(21.3)$ \\
\hline Total & $2346(100)$ \\
\hline
\end{tabular}

Table II: Accompanying diseases in cases with secondary SS

\begin{tabular}{|l|c|}
\hline Disease & n (\%) \\
\hline Rheumatoid arthritis & $44(49.4)$ \\
\hline Systemic lupus erythematosus & $13(14.7)$ \\
\hline Progressive systemic sclerosis & $13(14.7)$ \\
\hline Primary biliary cirrhosis & $7(7.8)$ \\
\hline Seronegative spondyloarthropathies & $6(6.7)$ \\
\hline Discoid lupus erythematosus & $3(3.4)$ \\
\hline Familial Mediterranean fever & $1(1.1)$ \\
\hline Multiple sclerosis & $1(1.1)$ \\
\hline Psoriasis & $1(1.1)$ \\
\hline Total & $89(100)$ \\
\hline
\end{tabular}


have LS 4 (OR 2.51, 95\% CI 1.42-4.44, p= 0.001) compared with ANA negative patients on logistic regression analysis but Anti-Ro test positivity was not significant (OR 1.29, 95\% CI 0.74-2.23, $\mathrm{p}=0.35$ ).

The Anti-Ro test results were also found to be statistically significant higher in secondary SS patients with LS 4 ( $\mathrm{p}=$ 0.048).

Table III presents the comparison of the clinical and autoantibody findings of the patients with primary and secondary SS by LS status.

\section{DISCUSSION}

Minor salivary gland biopsy is one of the methods used in SS diagnosis. Some studies report certain problems with its histopathological evaluation. Vivino et al. reported a major difference in almost half of the diagnoses of 60 MSGBs for which they were consulted. They emphasized that these inconsistencies will be minimized if the defined and accepted Chisholm criteria are meticulously used (9). Lymphocytic infiltration of LS 3 and over was found in 15\% of the MSGBs from 54 healthy cases in another study by Radfar F et al.

Table III: Comparison of the clinical and autoantibody findings of the patients with primary and secondary SS by LS status.

\begin{tabular}{|c|c|c|c|c|c|c|}
\hline \multirow{4}{*}{ Phenotypic features of SS } & \multicolumn{3}{|c|}{ Primary SS } & \multicolumn{3}{|c|}{ Secondary SS } \\
\hline & \multicolumn{2}{|c|}{ Lymphocyte score } & \multirow{3}{*}{$p$ value } & \multicolumn{2}{|c|}{ Lymphocyte score } & \multirow{3}{*}{ p value } \\
\hline & 3 & 4 & & 3 & 4 & \\
\hline & n (\%) & n (\%) & & n (\%) & n (\%) & \\
\hline \multicolumn{7}{|l|}{ Dry mouth symptoms } \\
\hline Present & $98(92.5)$ & $155(92.3)$ & \multirow{3}{*}{1.00} & $19(76)$ & $30(63.8)$ & \multirow{3}{*}{0.426} \\
\hline Absent & $8(7.5)$ & $13(7.7)$ & & $6(24)$ & $17(36.2)$ & \\
\hline Total & 106 & 168 & & 25 & 47 & \\
\hline \multicolumn{7}{|l|}{ Dry eye symptoms } \\
\hline Present & $101(95.3)$ & $158(93.5)$ & \multirow{3}{*}{0.607} & $19(76)$ & $30(63.8)$ & \multirow{3}{*}{0.426} \\
\hline Absent & $5(4.7)$ & $11(6.5)$ & & $6(24)$ & $17(36.2)$ & \\
\hline Total & 106 & 169 & & 25 & 47 & \\
\hline \multicolumn{7}{|l|}{ Schirmer's test } \\
\hline Positive & $77(72)$ & $113(68.1)$ & \multirow{3}{*}{0.590} & $20(66.7)$ & $15(38.5)$ & \multirow{3}{*}{0.029} \\
\hline Negative & $30(28)$ & $53(31.9)$ & & $10(33.3)$ & $24(61.5)$ & \\
\hline Total & 107 & 166 & & 30 & 39 & \\
\hline \multicolumn{7}{|l|}{ Anti-Ro (SS-A) } \\
\hline Positive & $39(36.1)$ & $84(50.6)$ & \multirow{3}{*}{0.025} & $3(8.8)$ & $13(27.7)$ & \multirow{3}{*}{0.048} \\
\hline Negative & $69(63.9)$ & $82(49.4)$ & & $31(91.2)$ & $34(72.3)$ & \\
\hline Total & 108 & 166 & & 34 & 47 & \\
\hline \multicolumn{7}{|l|}{ Anti-La (SS-B) } \\
\hline Positive & $22(20.4)$ & $51(30.7)$ & \multirow{3}{*}{0.069} & $2(5.9)$ & $4(8.5)$ & \multirow{3}{*}{1.00} \\
\hline Negative & $86(79.6)$ & $115(69.3)$ & & $32(94.1)$ & $43(91.5)$ & \\
\hline Total & 108 & 166 & & 34 & 47 & \\
\hline \multicolumn{7}{|l|}{ Antinuclear Antibodies } \\
\hline Positive & $59(54.6)$ & $130(77.4)$ & \multirow{3}{*}{0.001} & $17(50)$ & $25(52.1)$ & \multirow{3}{*}{1.00} \\
\hline Negative & $49(45.4)$ & $38(22.6)$ & & $17(50)$ & $23(47.9)$ & \\
\hline Total & 108 & 168 & & 34 & 48 & \\
\hline \multicolumn{7}{|l|}{ Rheumatoid Factor } \\
\hline Positive & $47(44.8)$ & $85(52.8)$ & \multirow{3}{*}{0.212} & $13(36.1)$ & $26(55.3)$ & \multirow{3}{*}{0.120} \\
\hline Negative & $58(55.2)$ & $76(47.2)$ & & $23(63.9)$ & $21(44.7)$ & \\
\hline Total & 105 & 161 & & 36 & 47 & \\
\hline
\end{tabular}

Patients whose clinical data could not be accessed were not included in the calculation. 
They believed that this could be due to various reasons including trauma as in habitual lip biting, subclinical infections and the early period of the disease (10).

Certain authors have questioned the contribution of MSGB to SS diagnosis and its necessity, considering that it is an invasive method that can produce false negative and false positive results (7). However, MSGB continues to be used in SS diagnosis as it is included in the American European Consensus criteria and has been reported to be helpful in the diagnosis in certain patient groups with non-specific clinical findings, extraglandular involvement, autoantibody negativity or during the early period of the disease (8). MSGB is also used during the evaluation of SS cases at our center.

Caporali et al. found the ratio of biopsies with at least one lymphoid focus to be $24.5 \%$ in their study including 435 patients (11). The ratio of the biopsies with a focus score of $\geq 1$ was found to be $42.7 \%$ among 120 biopsies in another study conducted by Morbini et al. (12). The ratio of the biopsies that were LS 3 or 4 was $38 \%$ in our study. We believe that this variability in the levels of LS ( 3 or 4 ) that may be used as a positive finding for SS could be related to the various approaches to the MSGB indication.

SS is a significant disease that is more commonly seen in females (F/M: 9/1) and in the 4th and 5th decades $(4,9,11,13)$. Females made up $93 \%$ of the cases in our study and the mean age was 53 years.

The primary disease was found to be rheumatoid arthritis (RA) in approximately half of our cases with secondary SS. The other two most common diseases were systemic lupus erythematosus (SLE) and progressive systemic sclerosis. The most common diseases accompanying secondary SS are reported as RA and SLE in the literature (14). No significant difference in terms of clinical findings was found between the LS 3 and LS 4 patient groups in our study while the Anti-Ro autoantibody was statistically significantly higher in LS 4 cases with secondary SS.

Daniels et al. found Anti-Ro/La, RF and ANA test results to be significantly higher in MSGB LS 3-4 cases when they evaluated 1726 patients (15). Carubbi et al. found no significant difference in terms of dry mouth, dry eye symptoms, ANA and RF positivity, and anti-La in their 794 patients they had divided into two groups as LS 1-2 and LS 3-4. However, Anti-Ro antibody was found to be significantly higher in their grade 3-4 cases (8). All of the cases with a Chisholm score of 3 or 4 had been diagnosed with SS and the Chisholm score was found to be related to ANA, RF, and Anti-Ro/La positivity in the study conducted by Yazısız et al. where they compared primary SS patients and those without SS (16). Most studies have compared LS 1-2 and 3-4 cases and only a few have compared LS 3 cases with LS 4 cases. Bamba et al. reported that the correlation of anti-Ro and anti-La antibodies increases with a positive biopsy when only LS 4 cases are accepted as a positive biopsy and that the biopsy score was found to be high (LS 4) in patients with both sicca symptom and positive antibodies (7). Vitali et al. reported that when the presence of a minimum of one lymphocytic focus (LS 3) in MSGB was considered to be positive for SS diagnosis, a sensitivity of $83.5 \%$ and specificity of $81.8 \%$ were found, and when a minimum of two lymphocytic foci (LS 4) was considered to be positive, the specificity increased (96.1\%), and the sensitivity decreased (68.3\%) (17).

In our study, the LS 3 and LS 4 groups were similar as regards dry mouth and eye symptoms and Schirmer test results but Anti-Ro and ANA positivity were significantly higher in primary SS cases with LS 4 . Anti-La positivity was higher in cases with LS 4 but the difference was not statistically significant. We believe that part (at least at a level that will create a statistically significant difference) of the cases with LS 4 on MSGB consist of cases whose SS findings have been relatively established and the autoantibody levels are therefore found to be higher. The diagnostic reliability of accepting cases with LS 3 but no antibody positivity as SS can only be determined with large series and long-term clinical follow-up.

We also found that LS of 3 or 4 in MSGB without dry mouth in $12.7 \%$ of the cases diagnosed with primary or secondary SS. One should therefore keep in mind that MSGB can be positive even in the absence of dry mouth in patients suspected of suffering from SS.

\section{ACKNOWLEDGEMENT}

The authors would like to thank Dr. Gül Kitapçıoglu for the statistical analysis.

\section{REFERENCES}

1. Fox RI. Sjogren's syndrome. Lancet. 2005;366:321-31.

2. Tezcan ME, Haznedaroğlu Ş. Secondary Sjögren's Syndrome: Sjögren's Syndrome and other connective tissue disorders. Turkiye Klinikleri J Immunol Rheumatol-Special Topics. 2012;5:6-10.

3. Peri Y, Agmon-Levin N, Theodor E, Shoenfeld Y. Sjögren's syndrome, the old and the new. Best Pract Res Clin Rheumatol. 2012;26:105-17.

4. Bayetto K, Logan RM. Sjogren's syndrome: A review of aetiology, pathogenesis, diagnosis and management. Aust Dent J. 2010;55 Suppl 1:39-47. 
5. Chisholm D, Mason D. Labial salivary gland biopsy in Sjogren's disease. J Clin Pathol. 1968;21:656-60.

6. Vitali C, Bombardieri S, Jonsson R, Moutsopoulos HM, Daniels TE, Fox IR, Kassan SS, Pillemer SR, Talal N, Weisman MH. Classification criteria for Sjogren's syndrome: A revised version of the European criteria proposed by American-European Consensus Group. Ann Rheum Dis. 2002;61:554-8.

7. Bamba R, Sweiss NJ, Langerman AJ, Taxy JB, Blair EA. The minor salivary gland biopsy as a diagnostic tool for Sjogren syndrome. Laryngoscope. 2009;119:1922-6.

8. Carubbi F, Alunno A, Cipriani P, Bartoloni E, Baldini C, Quartuccio L, Priori R, Valesini G, De Vita S, Bombardieri S, Gerli R, Giacomelli R. A retrospective, multicenter study evaluating the prognostic value of minor salivary gland histology in a large cohort of patients with primary Sjögren's syndrome. Lupus. 2015;24:315-20.

9. Vivino FB, Gala I, Hermann GA. Change in final diagnosis on second evaluation of labial minor salivary gland biopsies. J Rheumatol. 2002;29:938-44.

10. Radfar L, Kleiner DE, Fox PC, Pillemer SR. Prevalence and clinical significance of lymphocytic foci in minor salivary glands of healthy volunteers. J Rheumatol. 2002;29:938-44.

11. Caporali R, Bonacci E, Epis O, Bobbio-Pallavicini F, Morbini P, Montecucco C. Safety and usefulness of minor salivary gland biopsy: Retrospective analysis of 502 procedures performed at a single center. Arthritis Rheum. 2008;59:714-20.

12. Morbini P, Manzo A, Caporali R, Epis O, Villa C, Tinelli C, Solcia E, Montecucco C. Multilevel examination of minor salivary gland biopsy for Sjogren's syndrome significantly improves diagnostic performance of AECG classification criteria. Arthritis Res Ther. 2005; 7:343-8.
13. Cui G, Sugai S, Ogawa Y, Takeshita S, Masaki Y. Evaluation of the histologic criteria for diagnosis of Sjogren's syndrome. Nihon Rinsho Meneki Gakkai Kaishi. 1999;22:72-9.

14. Dafni UG, Tzioufas AG, Staikos P, Skopouli FN, Moutsopoulos HM. Prevalence of Sjogren's syndrome in a closed rural community. Ann Rheum Dis. 1997;56:521-5.

15. Daniels TE, Cox D, Shiboski CH, Schiødt M, Wu A, Lanfranchi H, Umehara H, Zhao Y, Challacombe S, Lam MY, De Souza Y, Schiødt J, Holm H, Bisio PA, Gandolfo MS, Sawaki T, Li M, Zhang W, Varghese-Jacob B, Ibsen P, Keszler A, Kurose N, Nojima T, Odell E, Criswell LA, Jordan R, Greenspan JS; Sjögren's International Collaborative Clinical Alliance Research Groups. Associations between salivary gland histopathologic diagnoses and phenotypic features of Sjögren's Syndrome (SS) among 1726 registry participants. Arthritis Rheum. 2011;63:2021-30.

16. Yazisiz V, Avci AB, Erbasan F, Kiriş E, Terzioğlu E. Diagnostic performance of minor salivary gland biopsy, serological and clinical data in Sjögren's syndrome: A retrospective analysis. Rheumatol Int. 2009;29:403-9.

17. Vitali C, Bombardieri S, Moutsopoulos HM, Coll J, Gerli R, Hatron PY, Kater L, Konttinen YT, Manthorpe R, Meyer O, Mosca M, Ostuni P, Pellerito RA, Pennec Y, Porter SR, Richards A, Sauvezie B, Schiødt M, Sciuto M, Shoenfeld Y, Skopouli FN, Smolen JS, Soromenho F, Tishler M, Wattiaux MJ. Assessment of the European classification criteria for Sjogren's syndrome in a series of clinically defined cases: Results of a prospective multicentre study, Ann Rheum Dis. 1996;55:116-21. 